\title{
Relation of Health Condition and Quality of Life: Examination of the Quality of Life of the Disadvantaged Population in Nyíregyháza by the FT Quality of Life Index ${ }^{1}$
}

\author{
Renáta Jávorné-ERdeI, Péter TAKács, Gergely Fábián \\ erdei.renata@foh.unideb.hu, takacs.peter@foh.unideb.hu, \\ fabian.gergely@foh.unideb.hu \\ (University of Debrecen, Debrecen, Hungary)
}

\section{Received: 20.01.2015; Accepted: 04.21.2015}

\begin{abstract}
Improving the health of the population, stopping and changing the disadvantage trends have long been one of the health policy objectives in the regions. Unfortunately in spite of the declared goals Hungary is far away from giving priority to health issues as they are not given proper attention either on individual or societal level. In modern societies local communities play an increasingly important role in the development of quality of life. Their activity, their influence over the power structures become dominant. Quality of life is made up of objective and subjective components. Their important sub-areas are health, financial situation, income situations, housing and social relationship.

Quality of life studies are the most frequent health-related research studies, the most remarkable results have been achieved here. Healthrelated quality of life is one of the most important and maybe the most frequently researched dimension of quality of life showing how much health status contributes to the welfare of the individuals. The primary objective of the research studies the improvement of the health status of the population and within it the health status of the individual as well as the reduction of health inequalities can be designated. The improvement of the quality of life can be rationalized as health benefit for the society. Its two main components are the extension of the life expectancy and the increase in numbers of the resulting years. The health of the Hungarian population is said to be unfavourable in international comparison and it
\end{abstract}

\footnotetext{
${ }^{1}$ The research was supported by the European Union and Hungary and was co-financed by the European Social Fund in the framework of TÁMOP 4.2.4. A/2-11-1-2012-0001 'National Excellence Program'.
} 
can also be stated that it is significantly poorer than it could be expected according to the socio-economic development level.

Keywords: health, subjective health status, life quality, health education

Before presenting the results of the research it is important to define the concept of the subjective, perceived health status and confirming its importance. Perceived health is based on the self-evaluation of the individual and is not necessarily connected closely with the medical diagnosis. In its assessment the social, economic situation and cultural roots play a key role. The definition of the sucjective health status is accepted in the international practice and it is a frequently applied tool in the health surveys of the population and it is a better predictor of mortality than any other indicators.

The revealing of the subjective perception of the health status appears in most questionnaire surveys as the respondents are able to assess their health status in a compex way. Evaluation of the self-assessed health status is in close connection with the objective health status making it suitable for monitoring disease processes (Pikó 2006).

Health approach in public health research surveys often follows the perceptional model when the determination of health is based on the own opinion of the person. Subjective, perceived health is offered as health indicator by several international organizations like OECD, WHO.

The European Health Interview Survey also contains a definition of the perceived health status: "Perceived health is based on the self-evaluation of the person, that is their opinion about their own health status. It is not related closely to the actual, medically proven diagnosis, its assessment is influenced by the social, economic, cultural situation of the person, however, it is an internationally accepted and frequently applied tool of the examinations concerning the health status of the population". (ELEF 2009 questionnaire)

\section{The Nyíregyháza panel study}

The Social Department of the Mayor's Office in Nyíregyháza and the Faculty of Health started an urban research series in 2008 for examining the quality of life among the residents of Nyíregyháza to analyze their health status and health behaviour and to explore the impacts of these factors on the quality of life.

The goal of this study is to describe the factors which influence the quality of life and to prepare a status description. 


\section{Methods}

The research program is based on international and national samples, which follows the methodology of the so called household panel. It collects information from urban households, and from the specified members of households. It tries to uncover the changes in the same population sample with the same questionnaire, which means the interviewers visit the same households at specific intervals.

The observation of household panels has an established methodology both in the European Union and in Hungary. The European Community Household Panel research can be regarded as an antecedent and partly as a model. It used a standardized questionnaire and identical samples (in a total of 60,500 European households, about 130,000 persons) between 1994 and 2001 for the observation of the living conditions of the European citizens in standardized dimensions. With its help income level, poverty, economic activity, health status and other factors can be compared at international level. There was some attrition in the sample due to the mobility of the population (moving to other places) and due to refusal of responding.

However, such data recording is necessary to have internationally comparable cross-sectional and longitudinal data.

The Hungarian antecedent of the investigation in Nyíregyháza was the national research titled Hungarian Household Panel started by TÁRKI at the beginning of the 1990's, which was conduced basically using the same methodology as the international surveys, and it monitors the trends and changes in the living conditions of the Hungarian households every two years.

\section{Data collection method}

The data collection of the theoretical and empirical questionnaire-based research covers the following topics:

1. Characteristics of households (composition of the household, housing conditions, problems, residential facilities and income)

2. Economic activity (characteristics related to work)

3. Health status (perceived health status, long-term diseases)

4. Social relationships (characteristics, extent and intensity of family and human relationships)

5. Situation of the elderly (the situation of 65-year-old or older inhabitants)

6. Support systems - social problems (characteristics of the natural and man-made safety nets, provision of benefits, opinions about the benefit systems and social care)

7. Operation of the Social Office (clients and their opinions)

8. Biography (personal characteristics of the respondents)

The selection of samples was based on the methodology of the Hungarian Household Panel. The sample includes only those citizens who are over 18 and have a permanent registered address in Nyíregyháza. The 
2.000 respondents and the additional 400 interviewees were randomly selected from the database of the Central Office of Administrative and Electronic Public Service.

The interviewers were the students of the University of Debrecen Faculty of Health. They had been prepared for this job and the respondents had been informed about the purpose and date of the interviewers' visit.

\section{Calculations}

Data processing and data analysis were performed with the help of SPSS for Windows statistical software package. One- and two-variable mathematical-statistical methods: (mean, standard deviation, frequency distribution, furthermore, two-sample t-test, independence test (chisquare test).

\section{Results}

This paper introduces a part of the overall research study, the examination of the quality of life of the income poor with the help of the FT quality of life index developed during the research.

The mortality indicators are generally the most favourable in the western region of Hungary, while the North plain and the North Hungarian regions have the worst indicators. From earlier surveys it is known that the inhabitants of Nyíregyháza usually regard their health conditions worse than the health conditions of the EU citizens. However, local data are close to the national data, so it would be an interesting topic of a further study to investigate why people from Nyíregyhaza judge their health status more unfavourable.

Indicators of the quality of life:

- The general welfare situation and living conditions of individuals or smaller or larger groups are expressed by numbers.

- The analyses related to the indicators play an important role in the comparison of the various communities (countries, regions, etc.)

- The index values indicate the communities' changes in their quality of life.

- During the research there was a need for an indicator that analyzes welfare conditions at urban level

The Rahman model was the base of the FT index developed by the colleagues of the University of Debrecen Faculty of Health. The FT index was developed in several steps. The first model worked with the simple sum of the involved variables, but in practice it proved to be sensitive when the interviewees refused to give responses. This is why the main component-based model was developed from the Rahman approach. Below it can be seen that from Rahman's eight sub-areas seven have been covered. There was no tight-fitting measuring point to emotional wellbeing so this one had to be left out. 
Figure 1

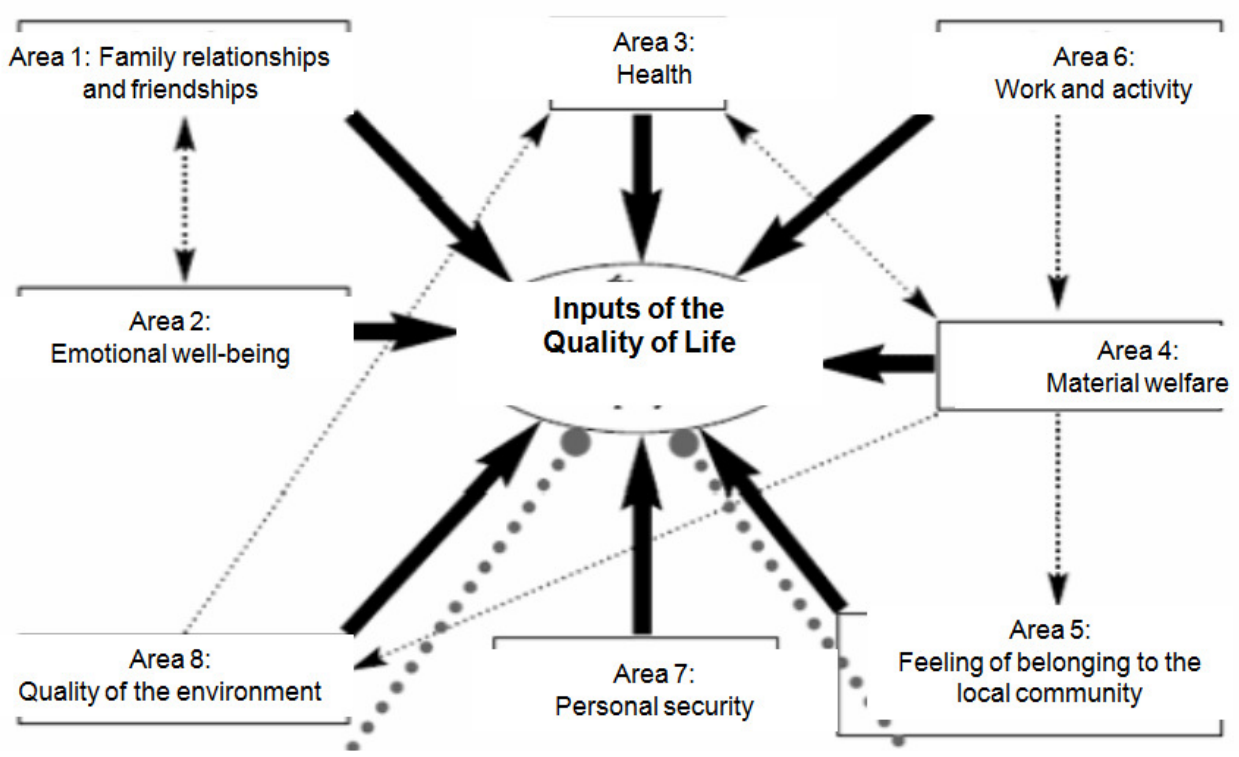

Questions of the specific partial areas have been combined by principal component analysis (Principal Component Analysis, PCA). The missing answers were replaced by group averages, thanks to which the number of missing responses decreased. All groups, consisting of multiple questions received an aggregate value during the procedure - auxiliary variables. The auxiliary variables have been involved in a weighted way during the formation of the index.

To determine disadvantageous situations several concepts have been developed and used. In our research the following definitions were used:

- Individuals and groups significantly different from the surrounding majority population, in an unfavourable direction, in a disadvantageous situation:

- People pushed to the periphery of the society

- The poor

- The unemployed

- Some ethnic minorities

- Groups exposed to frequent discrimination (e.g. Roma people, homosexuals, prostitutes)

The results of this study show the examination of the poor, income poor, financially deprivated disadvantageous respondents living in Nyíregyháza 161nt he basis of the 2012 inquiry.

This bar diagram shows the frequency of payment difficulties. While examining frequency distribution it became clear that only certain groups were involved. The main questions were: what connection could be found among the 6 studied issues and what was the connection between the 6 studied issues and the FT index? 
Figure 2

\section{Frequency of payment difficulties $(\%)$}

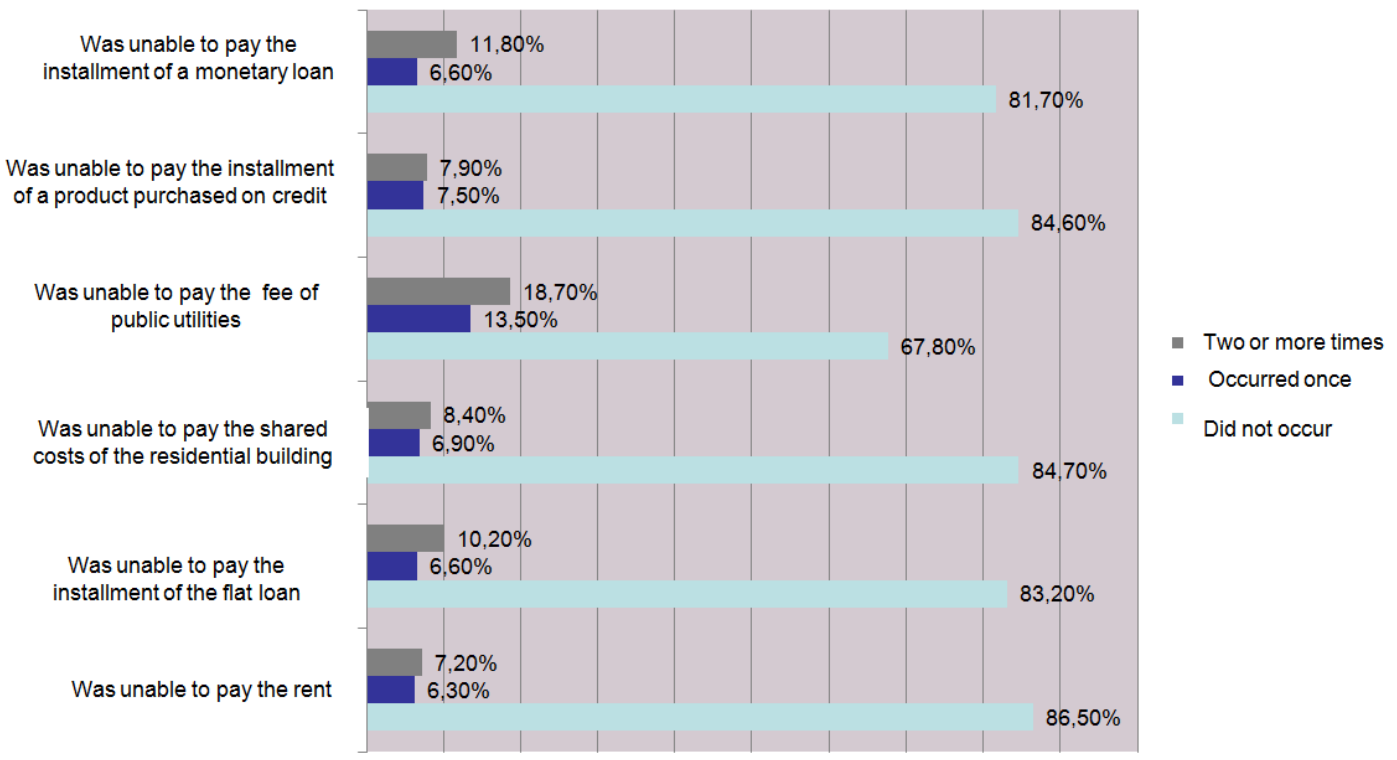

An important question was how the correlation was examined with the Spearman coefficient. Significance can be proved in each case. The strongest fit can be experienced between the difficulties how to pay the installments of the goods bought on credit and the difficulties how to pay the loan installments $162 \mathrm{nt} \mathrm{h}$ this case the value of the coefficient is above 0.4 .

Table 1

\begin{tabular}{|c|c|c|c|c|c|c|}
\hline $\begin{array}{l}\text { Textual description } \\
\text { of the variables }\end{array}$ & 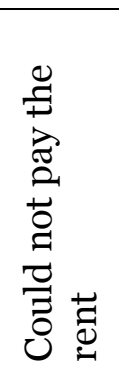 & 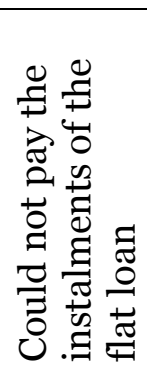 & 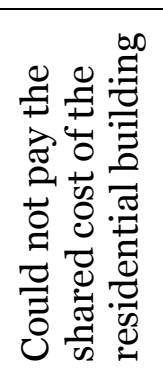 & 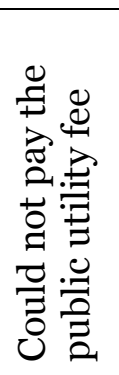 & 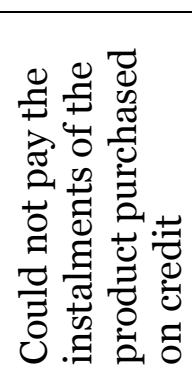 & 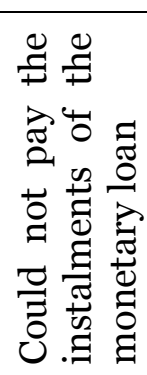 \\
\hline $\begin{array}{l}\text { Could not pay the } \\
\text { rent }\end{array}$ & 1.000 & ,570 & 601 & ,568 &, 504 &, 516 \\
\hline $\begin{array}{l}\text { Could not pay the } \\
\text { instalments of the } \\
\text { flat loan }\end{array}$ & ,570 & 1,000 & ,553 &, 583 & 661 &, 568 \\
\hline $\begin{array}{l}\text { Could not pay the } \\
\text { shared cost of the } \\
\text { residential building }\end{array}$ & ,601 & ,553 & 1,000 & ,604 & ,554 & ,420 \\
\hline $\begin{array}{l}\text { Could not pay the } \\
\text { public utility fee }\end{array}$ &, 568 &, 583 & ,604 & 1,000 & ,603 & ,662 \\
\hline $\begin{array}{l}\text { Could not pay the } \\
\text { instalments of the } \\
\text { product purchased } \\
\text { on credit }\end{array}$ &, 504 & 661 &, 554 & ,603 & 1,000 & ,804 \\
\hline $\begin{array}{l}\text { Could not pay the } \\
\text { instalments of the } \\
\text { monetary loan }\end{array}$ & ,516 &, 568 & ,420 & 662 & ,804 & 1,000 \\
\hline
\end{tabular}


The investigated focused 163nt he relationship between payment difficulties and the FT quality of life index.

One way variance analysis and non-parametric $\mathrm{K}-\mathrm{W}$ test were used to prove that the third group differs from the 1st and 2nd groups. The first two groups are mostly associated, in two cases the second group is between the other two and 1 and 3 always move separately (Figure 3).

Figure 3

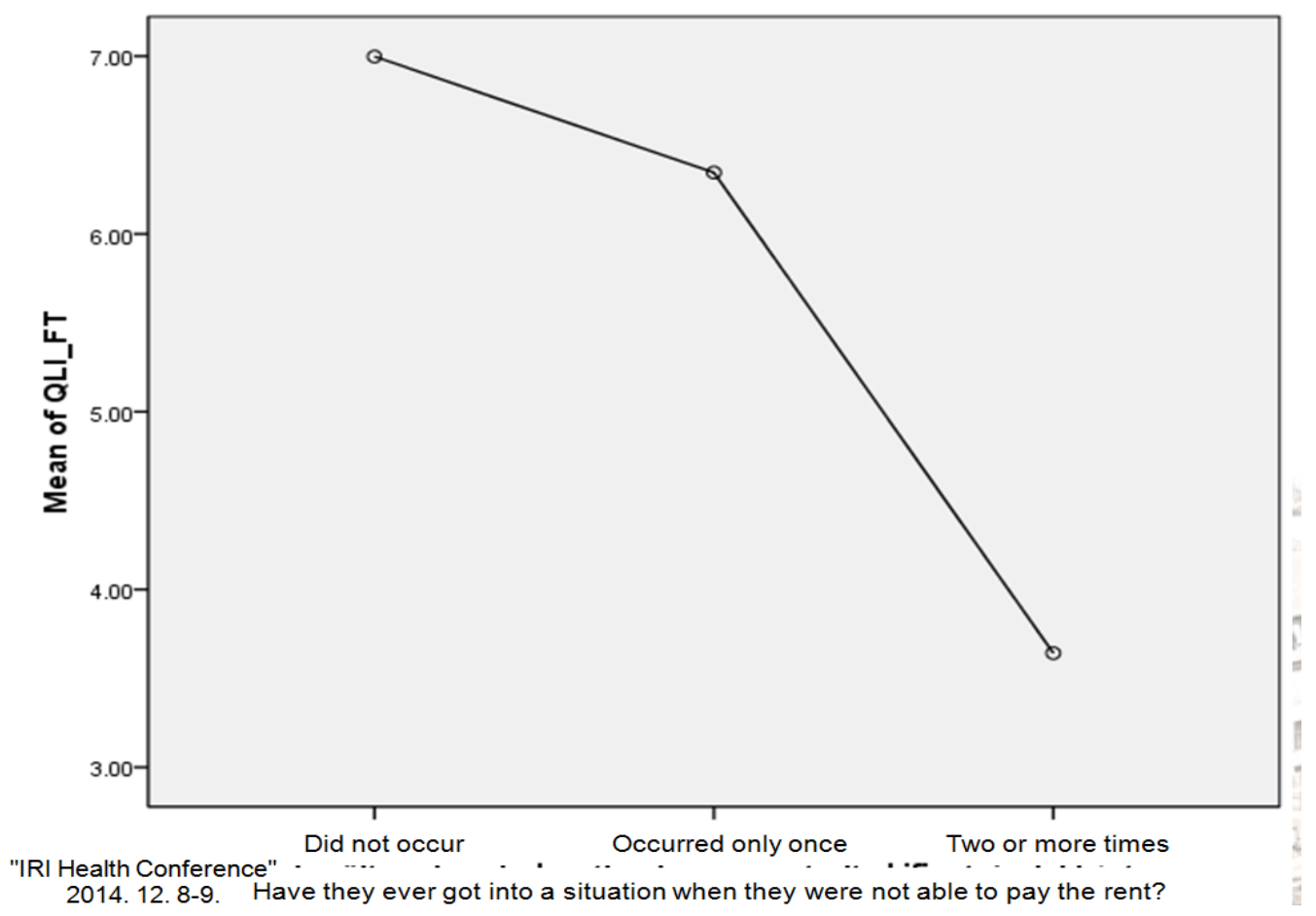

Another question was if the households could be groupped with the help of cluster analysis. On the basis of the 6 issues two groups developed. The not similar group averages caused a kind of assumption and this assumption was proved by ANOVA and K-W tests. On this basis two separate groups emerged. One of the groups contain the $77.5 \%$ of the respondents and $22.5 \%$ of the interviewees belong to the other group. Our qestion is who are they and what is the difference between these two groups?

The typical differences can be seen in the table below where the asterisk denotes significant differences. 
Table 2

\begin{tabular}{|l|c|c|}
\hline & $\begin{array}{c}\text { "those without any } \\
\text { difficulty" (\%) }\end{array}$ & $\begin{array}{c}\text { "those with a difficulty" } \\
\text { (\%) }\end{array}$ \\
\hline \multirow{2}{*}{ Marital status } & $\begin{array}{c}\text { Married, people with a } \\
\text { cohabiting partner: } 74.4\end{array}$ & $\begin{array}{c}\text { Married, people with a } \\
\text { cohabiting partner: } 62,9\end{array}$ \\
\cline { 2 - 3 } & Single: 25.6 & Single: 37.4 \\
\hline $\begin{array}{l}\text { Number of people living } \\
\text { in the same household }\end{array}$ & 1-2 persons: 53.8 & $1-2$ persons: 35.7 \\
\cline { 2 - 3 } $\begin{array}{l}\text { Can they afford to go on } \\
\text { vacation every year?* }\end{array}$ & 3 or more: 46.2 & 3 or more: 64.3 \\
\hline Meat consumption* & Yes:7 & Yes: 16.7 \\
\hline Smoking habits* & Every second day: 72.2 & Every second day: 58.9 \\
\hline Exhaustion* & Every day: 15 & Every day: 27.8 \\
\hline Nervousness* & 34.8 & 50 \\
\hline Depression* & 28.5 & 53.3 \\
\hline Tiredness* & 15.6 & 33.3 \\
\hline $\begin{array}{l}\text { Proportion of people with } \\
\text { disabilities* }\end{array}$ & Y0.2 5.2 & Yes: 13.6 \\
\hline Heating conditions* & Appropriate: 87.6 & Appropriate: 71.1 \\
\hline
\end{tabular}

\section{Summary}

The processing and analysis of data has not been finalized yet; they are only preliminary data in the study.

Clear differences can be found among the parts of Nyíregyháza. Expectations related to the assumption that in the districts of the city regarded or perceived poorer, the quality of life index has a lower average and in the parts of the city regarded to be richer, the average value of the index is higher, turned out to be true. The difference can be demonstrated also between the various economic "layers" (the poor, lower middle class, upper middle class, the rich). The index value increases with the growth of economic strength. There are sharp differences between the employment types. The quality of life index value of people with language certificate is higher. The single-aspect analysis of variance according to the number of rooms gives out sharp differences. The quality of life index of those having a car showed higher index values. The existence of work / workplace increases the index. The index value of male respondents is higher. According to the marital status, the index value of singles is lower. Higher educational attainment is associated with a higher index value. The very different response structure of religiousness, emerging from survey to survey is really surprising. According to health status, those declaring themselves in better medical condition have a higher index value as well. The quality of life index of individuals active from community aspect is higher. 